COMMENT. This prospective study shows that primary infection with HHV-6 or -7 is responsible for encephalopathy and/or severe convulsions with fever in $17 \%$ of children $<2$ years of age (median age 1 year) who require hospitalization. Primary HHV infection is not associated with the rash of exanthem subitum in one half the cases. CSF does not show evidence of direct viral involvement of the CNS, and the severe convulsions with fever could be classified as "complex febrile seizures." In the US, infection with HHV-6 accounts for one-third of all first-time febrile seizures in children $<2$ years old (Hall, Epstein, et al. $\mathbf{N}$ Engl J Med 1994;331:432-438; Ped Neur Briefs 2004;18:59). An elevated cytokine response independent of the severity of infection may be a factor in the mechanism of febrile seizures (Kawada et al, 2003; Millichap JG, Millichap JJ. J Infect Dis 2003;189:564).

Cytokines and febrile seizures. The height of the fever (not rate of rise) is the important determinant of a threshold to febrile seizures (Millichap, JG. Pediatrics 1959;23:76-85). Other FS causative factors related to infection include 1) an abnormal immune state and ailergic response to infection; 2) genetic susceptibility; 3) a neurotropic toxin (eg. Shigella) or virus (eg. HHV-6 or -7 , influenza A); 4) encephalopathy; and 5) an elevated cytokine response. Proinflammatory cytokines (interleukin-1B [IL-1B]) act as pyrogens, and fever induces IL-1B synthesis in brain microglia, leading to enhanced neuronal excitability and decreased seizure threshold. Dube $\mathrm{C}$ and colleagues (University of CA at Irvine) have shown that IL-1B receptor-deficient mice are resistant to experimental FS (Ann Neurol 2005;57:152-155). This resistance was independent of genetics and due to lack of IL1B signaling; high IL-1B doses induced seizures only in IL-1B receptor-expressing mice. The authors conclude that endogenous IL-1B contributes to FS, and potentially contributes to hippocampal epilepsy. Further investigation of viral and cytokine-related factors in the cause of simple and complex febrile seizures is indicated.

\title{
DIFFERENTIATION OF ADEM AND MS AT PRESENTATION
}

The clinical features of published case series of acute disseminated encephalomyelitis (ADEM) and multiple sclerosis (MS) are reviewed at the Institute of Neurology, Queen Square, London. Differences in presentation of the two disorders may help in the early diagnosis, in the absence of a reliable diagnostic test for MS. Monophasic ADEM is more common in children $<10$ years old whereas MS usually presents at $>10$ years, and only 2.7 $4.4 \%$ of cases of MS occur under 16 years of age. A precipitating infection is common in ADEM and unusual in MS. ADEM presents with signs of encephalopathy or encephalitis (headache, vomiting, drowsiness, meningism, and seizures in 13-35\%), but these symptoms are uncommon in MS. Optic neuritis is bilateral in ADEM and unilateral in MS. CSF shows increased protein and lymphocytosis in ADEM, and oligoclonal bands in MS. Both ADEM and MS show disseminated inflammatory demyelinative lesions on brain MRI; these are cortical and in deep grey matter in ADEM and periventricular/callosal lesions in MS. Followup MRI shows no new lesions in ADEM, and relapse with additional lesions after 6 months in MS. (Dale RC, Branson JA. Acute disseminated encephalomyelitis or multiple sclerosis: can the initial presentation help in establishing a correct diagnosis? Arch Dis Child June 2005;90:636-639). (Respond: Dr RC Dale, Neuroimmunology Laboratory, $9^{\text {th }}$ Floor, Institute of Neurology, Queen Square, London WC1N 3BG, UK). 
COMMENT. The differentiating factors for ADEM and MS outlined above are useful when considered as a group of presenting characteristics, but individually their value is limited. In an analysis of initial MRI findings predictive of a second attack of acute CNS inflammatory demyelination in 116 children, Mikaeloff et al found that the risk of MS was significantly higher in patients with corpus callosal lesions, whereas basal ganglia lesions were equally frequent in monophasic (ADEM) and recurrent (MS) disease (Brain 2004;127:1942-1947; Ped Neur Briefs 2004;18:65-66). Tenembaum et al (2002) found relapses and MS in $10 \%$ cases initially diagnosed as ADEM; residual disability was not related to MRI findings at onset, but it was correlated with the occurrence of optic neuritis (Ped Neur Briefs 2002;16:81).

\section{ATTENTION DEFICIT HYPERACTIVITY DISORDER}

\section{LONG-TERM EFFECTS OF ADDERALL XR IN ADHD}

The long-term tolerability and effectiveness of extended release mixed amphetamine salts (Adderall XR) in children with attention deficit hyperactivity disorder (ADHD) were evaluated in a 24-month, multicenter, open-label extension of 2 placebo-controlled studies at UCLA, Massachusetts General Hospital, UC-Irvine, Maitland, FL, and Shire Pharmaceutical, Wayne, PA. The initial dose of Adderall XR was $10 \mathrm{mg}$ daily in 568 children, aged 6-12 years, and was increased by $10 \mathrm{mg}$ weekly to optimal effective levels (maximum $30 \mathrm{mg} / \mathrm{d}$ ). Quarterly Conners Global Index Scale, Parent version (CGIS-P) was used to assess effectiveness, and adverse events, physical examinations, and laboratory tests were monitored to assess tolerability. Significant improvements $(>30 \%, \mathrm{p}<0.001)$ in CGIS-P scores were maintained through the trial, and treatment was generally well tolerated. Adverse events $(\mathrm{AE})$ included headache $(15 \%)$, anorexia $(15 \%)$, and insomnia $(11 \%) ; 15 \%$ withdrew from the study because of $\mathrm{AE}$ (weight loss, anorexia, insomnia, depression, and emotional lability). Serious $\mathrm{AE}$ were reported in 18 subjects (3\%); only 2, both convulsions, were judged possibly drug-related, at doses of 10 and $20 \mathrm{mg} / \mathrm{d}$. None required subsequent treatment with anticonvulsants. Mean systolic blood pressure increased by $3.5 \mathrm{mmHg}$, diastolic by $2.6 \mathrm{mmHg}$, pulse by 3.4 beats per min. (Changes in vital signs, ECG, and cardiovascular-related AEs to be reported later). (McGough JJ, Biederman J, Wigal SB et al. Long-term tolerahility and effectiveness of once-daily mixed amphetamine salts (1dderall XR) in children with ADHD. J Am Acad Child Adolescent Psychiatry June 2005;44:530538). (Reprints: Dr McGough, 300 UCLA Medical Plaza, Suite 1414, Los Angeles, CA 90095).

COMMENT. This paper is something of a cliff-hanger. The promise of a second installment in a subsequent publication is frustrating. The effectiveness and general tolerability of Adderall XR is well known, but answers to the concerns regarding cardiovascular events are anxiously awaited. Hopefully, we can expect this report soon.

Atomoxetine-induced blood pressure increase. A significant elevation in blood pressure is noted in 3 adolescent boys while taking doses of $80 \mathrm{mg} /$ day atomoxetine (Dworkin N. J Am Acad Child Adolesc Psychiatry June 2005;44:510). Other drugs were given in combination, compromising the significance of the report, but our own practice of monitoring BP, pulse, height, and weight regularly in ADHD patients will be continued. 